\title{
Variability of plasma melatonin level in pony mares (Equus caballus), comparison with the hybrid: mules and with jennies (Equus asinus)
}

\author{
Daniel Guillaume*, Luiz A. ZaraZaga, Benoît MalPauX, \\ Philippe CHEMINEAU
}

\begin{abstract}
Neurobiologie et maîtrise des fonctions saisonnières, UMR 6175 INRA-CNRS-Université de ToursHaras Nationaux, Physiologie de la Reproduction et des Comportements, 37380 Nouzilly, France
\end{abstract}

(Received 13 October 2005; accepted 7 July 2006)

\begin{abstract}
In long-day breeders like horses, the length of nocturnal melatonin secretion is the main messenger of photoperiod. Previous studies have shown that the nocturnal jugular melatonin concentration is lower in horses, than in mules but is unknown in donkeys. The aim of this study was to estimate the inter-animal variability of plasma melatonin concentration in domestic mares and to compare this concentration with those observed in domestic jennies and in their hybrid mules. In the autumn, blood samples were collected at $22 \mathrm{~h}, 23 \mathrm{~h}, 0 \mathrm{~h}$ and $1 \mathrm{~h}$ during 2 nights at 3 weeks intervals, in 110 pony mares, 10 jennies and 6 mules maintained under natural photoperiod. Melatonin was assayed by a validated RIA method. The statistical analysis of the measures was done with a specific unbalanced analysis of variance model. The effect of species and individuals (nested under species) was highly significant. The mean melatonin concentration was $24 \mathrm{pg} . \mathrm{mL}^{-1}$ in mares and was significantly lower than in jennies and in mules which were $90 \mathrm{pg} \cdot \mathrm{mL}^{-1}$ and $169 \mathrm{pg} \cdot \mathrm{mL}^{-1}$ respectively. The melatonin plasma concentration was higher in jennies than in mares. These results suggest that the melatonin concentration is genetically determined.
\end{abstract}

melatonin / equine species / genetic / photoperiod

\section{INTRODUCTION}

Equines and hamsters are long-day breeders. In mares, after the anovulatory period during the autumn and winter, the date of the first annual ovulation is significantly advanced by a light treatment of $14.5 \mathrm{~L} ; 9.5 \mathrm{D}$ beginning around the winter solstice [1]. In horses, the role of melatonin has only been investigated in the regulation of reproduction. Melatonin is secreted only during the night by the pineal

\footnotetext{
* Corresponding author: dguillau@ tours.inra.fr
}

gland. The length of nocturnal melatonin secretion is the main messenger of photoperiod in reproduction [2]. This level increases immediately after the sunset and decreases with the sunrise and shows irregular peaks all during the night. The total melatonin production rate is proportional to the night duration [3]. In contrast, the nocturnal plasmatic melatonin concentration appears unrelated to the reproductive status, and some mares showing no cyclicity in the winter do not exhibit a rise in plasmatic melatonin values during darkness [4]. 
In jennies, an anovulatory period during the autumn and winter is also observed with approximately the same characteristics as in mares [5]. In Donkeys, no data are available on the effect of light and/or melatonin treatment on the end of the sexual inactivity in winter and on nocturnal melatonin concentration.

Some female mules (jack donkey $\times$ mare), present a complete genital tract with functional ovaries. These animals are generally sterile but some cases of conception have been described [6,7]. A few mules show regular cyclicity but most of them have irregular periods without ovulation. So it is difficult to characterise winter ovarian inactivity in this hybrid [8]. A previous study showed [9] that the nocturnal jugular melatonin concentration was high in mules, probably higher than in horses.

In humans [10] as in ewes [11], it is reported that, from one night to another, the nocturnal variation of melatonin level seems to be very stable, within the same individuals, but high variability exists between individuals. This suggests that the nocturnal melatonin level is genetically determined. The genetic control of nocturnal variability in melatonin level is well demonstrated in humans [12] and in ewes [13]. In equine species, it is almost impossible to find a sufficiently large herd, in the same place, with an appropriate genetic structure to calculate the genetic parameters of the nocturnal melatonin level.

The aims of this study were the following:

- to estimate the nocturnal melatonin level, its variability between individuals and its frequency of distribution;

- to verify if the hypothesis of a genetic determinism of melatonin concentration can be supported by the comparison of this level in the 2 parental species and in their hybrid.

\section{MATERIALS AND METHODS}

\subsection{Animals}

A total of 110 Welsh pony mares and 6 mules of the experimental herd of INRA in Tours (48 north latitude), 10 jennies of the experimental herd of the Veterinarian School in Nantes (48 north latitude), kept under natural photoperiod, were used in this experiment.

In a previous study, we verified that these mules were really interspecific hybrids. The karyotype analysis of the 6 assumed mules was determined by analysis of lymphocyte metaphases. Their karyotype $(2 \mathrm{n}=63)$ was composed of one donkey set $(\mathrm{n}=31)$ and one horse haploid complement $(\mathrm{n}=32)$.

\subsection{Blood sampling}

Blood samples were collected on the left jugular vein with heparinised tubes (Vacutainer ${ }^{\circledR}$ Vecton-Dixon), from the left jugular vein, in the usual stable of these animals, during a first night, in the autumn, at $22 \mathrm{~h}, 23 \mathrm{~h}, 0 \mathrm{~h}$ and $1 \mathrm{~h}$ and during a second night, 3 weeks later, at the same hours. During natural darkness the mares were attached and samples were collected using a low red light intensity red lamp worn on the experimenter's head $(<1$ lux at $20 \mathrm{~cm}$ ). Blood was immediately centrifuged and plasma was stored at $-20{ }^{\circ} \mathrm{C}$ until melatonin assays.

\subsection{Melatonin assay}

Plasma melatonin concentration was measured with a specific radio immunoassay [14]. We previously verified that the total binding fraction was the same in free melatonin plasma from the 2 species and their hybrid. To calculate the concentration, the standards from $1.25 \mathrm{pg} . \mathrm{mL}^{-1}$ to 
Table I. Nocturnal plasma melatonin concentration (arithmetical means + S.E.M.).

\begin{tabular}{llll}
\hline & 1st week & 2nd week & Global \\
\hline 110 pony mares & $22 \pm 1 \mathrm{pg} \cdot \mathrm{mL}^{-1}$ & $26 \pm 1 \mathrm{pg} \cdot \mathrm{mL}^{-1}$ & $24 \pm 1 \mathrm{pg} \cdot \mathrm{mL}^{-1}$ \\
10 jennies & $70 \pm 8 \mathrm{pg} \cdot \mathrm{mL}^{-1}$ & $105 \pm 15 \mathrm{pg} \cdot \mathrm{mL}^{-1}$ & $91 \pm 10 \mathrm{pg} \cdot \mathrm{mL}^{-1}$ \\
6 mules & $215 \pm 41 \mathrm{pg} \cdot \mathrm{mL}^{-1}$ & $125 \pm 16 \mathrm{pg} \cdot \mathrm{mL}^{-1}$ & $169 \pm 22 \mathrm{pg} \cdot \mathrm{mL}^{-1}$ \\
\hline
\end{tabular}

5000 pg. $\mathrm{mL}^{-1}$, were made in mare low melatonin plasma. This plasma was chosen from a group of plasma samples collected during the daytime and presenting the highest binding radioactivity. On these standards, a 4 parameter logistic function was estimated using the SAS software. All samples collected in the 2 species and in the hybrid were twice measured in the same assay. The place of each sample was randomly assigned and the 2 assay tubes were not treated successively but independently. The sensibility of this assay was $5 \mathrm{pg} \cdot \mathrm{mL}^{-1}$. The superior limit of quantification, where the measured radioactivity was significantly different from the non-specific binding was 500 pg. $\mathrm{mL}^{-1}$. One day sample, one sample with mixed night and day plasma, one night sample and one sample with exogenous melatonin were routinely used as quality controls and were put, every 100 samples. Their concentrations were respectively the following: not detectable, 5 pg.mL ${ }^{-1}, 15$ pg. $\mathrm{mL}^{-1}, 535$ pg. $\mathrm{mL}^{-1}$ with intra-assay variation coefficients of respectively $35 \%, 13 \%$ and $20 \%$. The first and the last values were near the limits of quantification of the assay.

\subsection{Statistical analysis}

In order to test if the frequency distribution curve is near the normality or not, the flatness coefficient of Kurtosis $\alpha_{4}$ (with $\alpha_{4}=\mathrm{m}_{4} /\left(\mathrm{m}_{2}\right)^{2}$ where $\mathrm{m}_{n}$ is the order $n$ central moment) and the skewness coefficient $\alpha_{3}$ (with $\alpha_{3}=\mathrm{m}_{3} /\left(\mathrm{m}_{2}\right)^{3 / 2}$ ) were used.
These two coefficients, $\alpha_{4}$ and $\alpha_{3}$, calculated before and after log transformation are compared to the theoretical value obtained for the Gauss curve: 0 .

The statistical analysis was done with specific unbalanced analysis of variance after log transformation with SAS software. A first analysis was done for the inter animal variability in which species and animals were the main factor; the error term for the species effects was individual effects nested under species. A second analysis for the inter-animal variability used a repeated data model considering the following factors: species, individual nested under species, collection weeks, collection hours and the appropriate interactions. For the different time effects the error term is the appropriate interaction. On the significant effect, L.S. mean differences were tested on the appropriate interaction.

\section{RESULTS}

The means of nocturnal melatonin concentration in each species for each week are presented in the Table I.

The distribution of frequency of melatonin concentration in the different types of animals is presented in Figure 1. On this curve, the flatness coefficient of Kurtosis, $\alpha_{4}$ and the skewness coefficient, $\alpha_{3}$ are 110.1 and 8.1, respectively. For each group, the inter-animal variability is very important. The number of mares with a very low concentration of nocturnal melatonin is important: $35 \%$ of mares have melatonin concentration lower 




Figure 1. Number of animals per class of melatonin level (mean for 2 nights of nocturnal plasma concentration).

than 10 pg.mL ${ }^{-1}, 30 \%$ between 10 and 20 pg. $\mathrm{mL}^{-1}$ and $35 \%$ between 20 and 130 pg.mL $\mathrm{mL}^{-1}$. Ten per cent of the mares never showed a melatonin elevation higher than 10 pg. $\mathrm{mL}^{-1}$ in the 8 blood samples. The repartition of the mares was not normal but was well normalised by a log. transformation (Fig. 2). After log transformation the coefficients $\alpha_{4}$ and $\alpha_{3}$ were -0.5 and -0.2 , respectively. They were not different from the theoretical value 0 . All 10 jennies had melatonin concentrations higher than $20 \mathrm{pg} \cdot \mathrm{mL}^{-1}$ and 3 of them were higher than $100 \mathrm{pg} \cdot \mathrm{mL}^{-1}$. All 6 mules had a melatonin concentration higher than 50 pg. $\mathrm{mL}^{-1}$ and 2 of them higher than 300 pg. $\mathrm{mL}^{-1}$.

The species effect was highly significant $(P<0.0001)$. The melatonin concentration is significantly $(P<0.0001)$ lower in mares than in mules and in jennies but did not differ significantly $(P=0.3)$ between mules and jennies.

The effect of the hour of the blood sample collection was not significant $(P=$ $0.6)$. The week effect and the interaction species-weeks were not significant $(P=$ 0.9 and 0.5 respectively).

\section{DISCUSSION AND CONCLUSION}

In the two species and in their hybrid the melatonin concentration was very stable between one night and another. This stability is probably the result of a strong individual determinism. In these 110 mares, an attempt was made to study the genetic effect but the genetic structure of our experimental breed was not well adapted for this type of study and the heritability of 


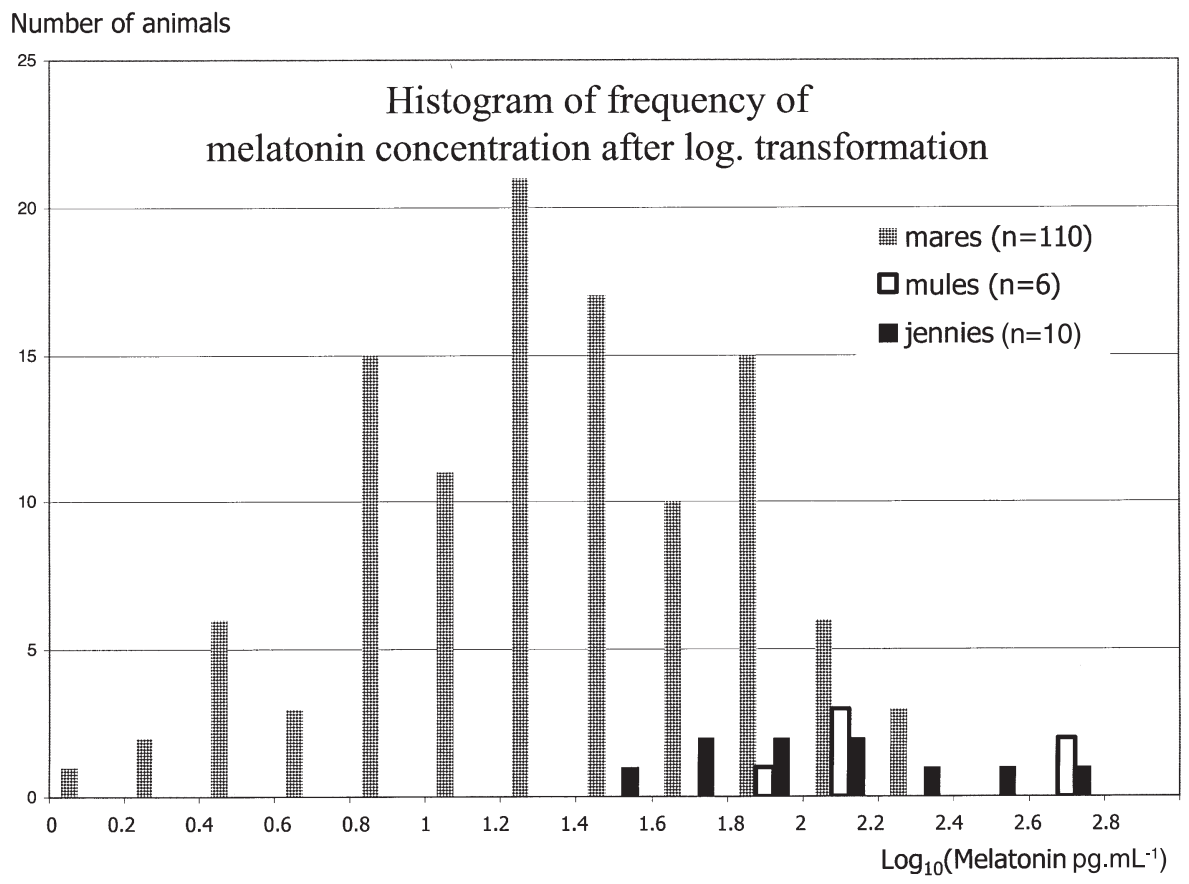

Figure 2. Number of animals per class of melatonin level (mean for 2 nights nocturnal plasma concentration) after log transformation.

the melatonin level cannot be valuably estimated.

A lot of mares presented a low average concentration of nocturnal plasmatic melatonin, and some of these mares never showed an increase higher than 10 pg.mL $\mathrm{mL}^{-1}$ during the night time. These results confirmed those of Fitzgerald and Schmidt [4]. Melatonin, in mares as in other species, play a major role in the determinism of winter ovarian inactivity. The first ovulation is advanced by a photostimulation and exogenous melatonin suppresses this photostimulation [2] but some mares have no nocturnal melatonin increase and show winter ovarian inactivity [4]. In ovine species, the intraventricular melatonin concentration is higher than in blood $[15,16]$; this is probably the same in the equine species. These observations suggest that, in the equine species, the main route of melatonin in the direction of the reproduction axis is not the general blood circulation but probably the cerebrospinal fluid through the third ventricle. This hypothesis is sustained in ewes by Tricoire et al. [17]; in this species melatonin acts on the reproduction axis via the mediobasal hypothalamus [18].

In mules the high melatonin concentration [9] is well confirmed. This concentration cannot explain the general sterility of mules as Cozzi et al. [9] supposed; this concentration is comparable with the concentration found in jennies or in ovine species with a similar RIA using the same antibody [11].

This is the first study on the melatonin concentration in jennies. This concentration is higher than in mares and lower, but not significantly, than in mules. The jennies were not blood sampled in the same 
place as mares or mules, so the melatonin concentration was probably underestimated.

The melatonin concentration is higher in the interspecific hybrid than in horses and higher in donkeys than in horses. These results suggest that the melatonin concentration is genetically determined. The principal component of the high concentration of melatonin in the mules comes from the jennies. These results confirm the high heritability observed by Wetterberger et al. [12] in humans and by Zarazaga et al. [13] in ewes (respectively $\mathrm{h}^{2}=0.53$ and $\mathrm{h}^{2}=0.45$ ). The interspecific hybrid between horses and donkeys could be an interesting model to study the genetic determinism of endocrine level.

\section{ACKNOWLEDGEMENTS}

We thank Dr L. Bodin (SAGA INRA, 31326 Castanet-Tolosan, France) for a preliminary statistical analysis, Dr E.P. Cribiu (Génétique biochimique et Cytogénétique INRA, 78000 Jouy-en-Josas, France) for the karyotype of the 6 mules, Dr I. Battut and Dr D. Tainturier (National veterinary school, Nantes, France) for lending the jennies, Dr S. Boyazoglu for mule care, M. Gibelin and G. Duchamp, (INRA, 37380 Nouzilly, France) for organising the blood collection, The staff from the P.R.M.D. experimental farm for mare and mule care, $\mathrm{S}$. Heuclin (INRA, 37380 Nouzilly, France) for technical assistance during the melatonin assays, Dr C. Briant (INRA, 37380 Nouzilly, France) for critical reading of the manuscript.

\section{REFERENCES}

[1] Palmer E, Driancourt MA, Ortavant R. Photoperiodic stimulation of the mare during winter anoestrus. J Reprod Fertil Suppl 1982, 32: 275-282.
[2] Guillaume D, Palmer E. Effect of oral melatonin on the date of the first ovulation after ovarian inactivity of mares under artificial photoperiod. J Reprod Fertil Suppl 1991, 44: 249-257.

[3] Guillaume D, Rio N, Toutain PL. Kinetic studies and production rate of melatonin in pony mares. Am J Physiol 1995, 268: R1236-R1241.

[4] Fitzgerald BP, Schmidt MJ. Absence of an association between melatonin and reproductive activity in mares during the nonbreeding season. Biol Reprod Monogr Ser 1995, 1: 425-434.

[5] Ginther OJ, Scraba ST, Bergleft DR. Reproductive seasonality of the jennies. Theriogenology 1987, 27: 587-592.

[6] Rong R, Chandley AC, Song J, McBeath S, Tan PP, Bai Q, Speed RD. A fertile mule and hinny in China. Cytogenet Cell Genet 1988, 47: 134-139.

[7] Henry M, Gastal EL, Pinheiro LEL, Guimaraes SEF. Mating pattern and chromosome analysis of a mule and her offspring. Biol Reprod, Monogr Ser 1995, 1: 273-279.

[8] Nishikawa Y. Studies on reproduction in horses. Jap Racing Ass, Shiba Tamuracho Minatokou, Tokio 1959.

[9] Cozzi B, Morei G, Ravault JP, Chesneau D, Reiter RJ. Circadian and seasonal rhythms of melatonin production in mules (Equus asinus $\times$ Equus caballus). J Pineal Res 1991, 10: $130-135$.

[10] Arendt J. Clinical perspectives for melatonin and its agonists. Biol Psychiatry 1994, 35: $1-2$.

[11] Chemineau P, Maurice F, Daveau A. Reinitialisation of ovulatory activity by melatonin given as a constant-release implant in long-day treated Ile-de-France ewes, depends on endogenous secretion of melatonin. In: Touitou Y, Arendt J, Pevet P (Eds), Melatonin and the pineal gland, from basic science to clinical application, Satellite symposium of the IXth international congress of endocrinology, 6-9 September 1992, Paris, France 1993, pp 247-250.

[12] Wetterberger L, Iselius L, Lindsten J. Genetic regulation of melatonin excretion in urine. Clinical Genet. 1983, 24: 399-402. 
[13] Zarazaga LA, Malpaux B, Bodin L, Chemineau P. The large variability in melatonin blood levels in ewes is under strong genetic control. Am J Physiol 1998, 274: E607-E610.

[14] Tillet Y, Ravault JP, Selve C, Evin G, Castro B, Dubois MP. Conditions d'utilisation d'anticorps spécifiques pour la visualisation immunohistochimique de la sérotonine et de la mélatonine dans la glande pinéale du mouton. C R Acad Sci Paris 1986, 303: 77-82.

[15] Rollag MD, Morgan RJ, Niswender GD Route of melatonin secretion in sheep. Endocrinology 1978, 102: 1-8.
[16] Tricoire H, Locatelli A, Chemineau P Malpaux B. Melatonin enters the cerebrospinal fluid through the pineal recess. Endocrinology 2002, 143: 84-90.

[17] Tricoire H, Moller M, Chemineau P Malpaux B. Origin of cerebrospinal fluid melatonin and possible function in the integration of photoperiod. Reprod Suppl 2003, 61: 311-321.

[18] Malpaux B, Daveau A, Maurice F, Gayard V, Thiery JC. Short days effects of melatonin on LH secretion in the ewe: evidence for central sites of action in the mediobasal hypothalamus. Biol Reprod 1993, 48: 752-760. 